\title{
Immediate improvement of left internal thoracic artery graft flow after subclavian artery stenting
}

\author{
Ahmet Goktug Ertem¹, Harun Kilic², Ugur Arslantas², Ekrem Yeter ${ }^{2}$ \\ 'Department of Cardiology, Ankara Ataturk Education and Training Hospital, Ankara, Turkey \\ ${ }^{2}$ Department of Cardiology, Diskapi Yildirim Beyazit Education and Training Hospital, Ankara, Turkey
}

Postep Kardiol Inter 2014; 10, 3 (37): 209-210 DOI: $10.5114 /$ pwki.2014.45150

\begin{abstract}
A bstract
We report a case of treatment of subclavian-coronary steal syndrome with stenting and immediate improvement of left internal mammalian artery flow.
\end{abstract}

Key words: stenting, subclavian-coronary steal syndrome.

A 65-year-old man was admitted to the emergency department with chest and arm pain ongoing for one hour. He had a history of anterior myocardial infarction (MI) with coronary artery bypass graft (CABG) operation (left anterior descending artery (LAD) - left internal thoracic artery (ITA), left circumflex artery (LCX) - radial artery, and right coronary artery (RCA) - saphenous vein conduits), diabetes mellitus (DM) with oral medication, and hypertension (HT). On physical examination there was weakness of left arm pulse and lower left arm blood pressure $(90 / 60 \mathrm{~mm} \mathrm{Hg}$, right arm blood pressure was 140/90 mm Hg). His electrocardiography (ECG) revealed old left bundle branch block (LBBB) (Sgarbossa criteria: 2 points) (Figure 1). His laboratory findings showed in-

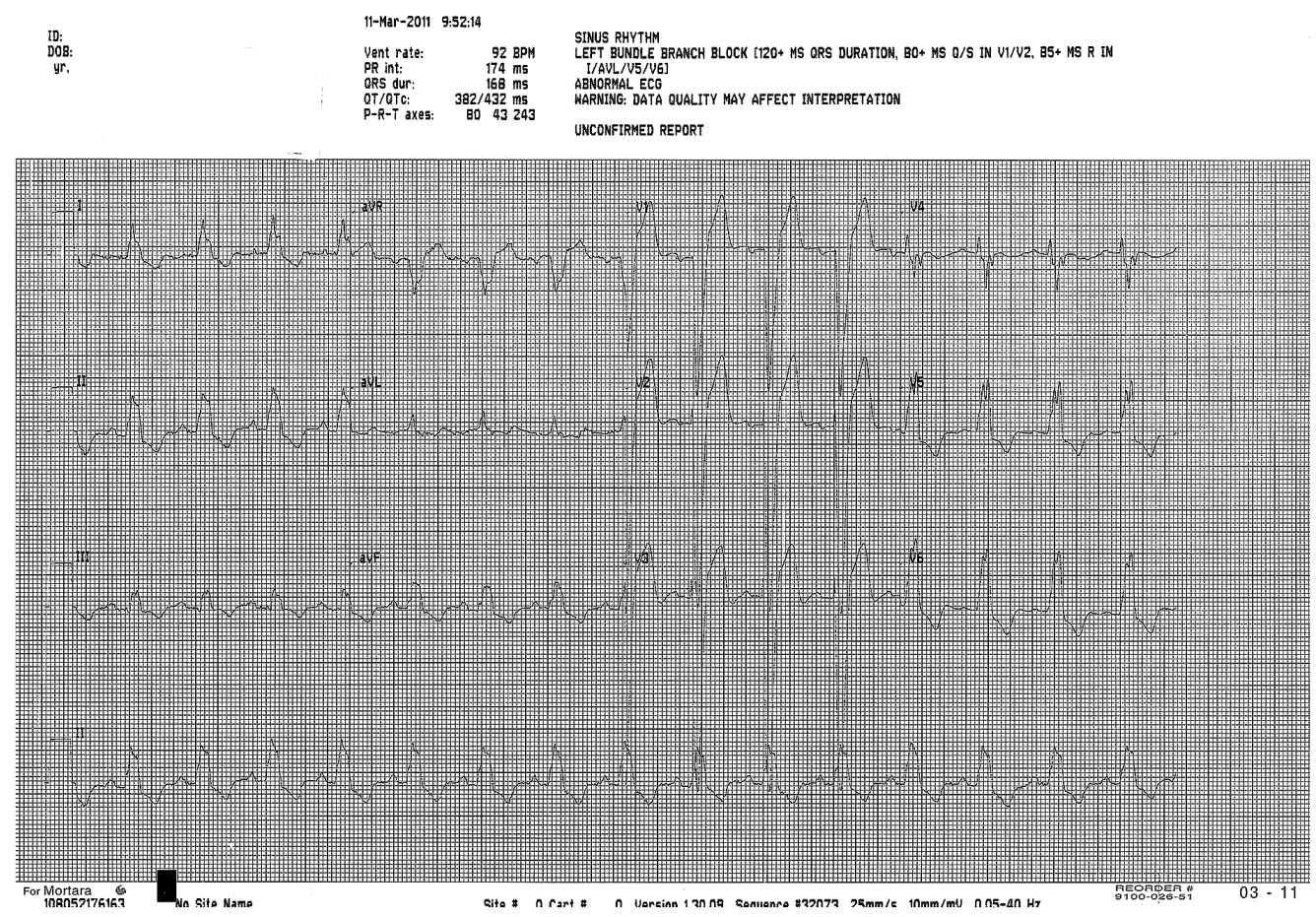

Figure 1. Electrocardiography of the patient on admission, demonstrating left bundle branch block (LBBB)

\section{Corresponding author:}

Ahmet Goktug Ertem MD, Department of Cardiology, Ankara Ataturk Education and Training Hospital, Sogutozu Konutlari, Sogutozu Mah. 2185. Sk. 7/A No: 56 Cankaya, 06510 Ankara, Turkey, phone: +905323944334, e-mail: agertem@hotmail.com

Received: 12.01 .2014 , accepted: 12.02 .2014$. 


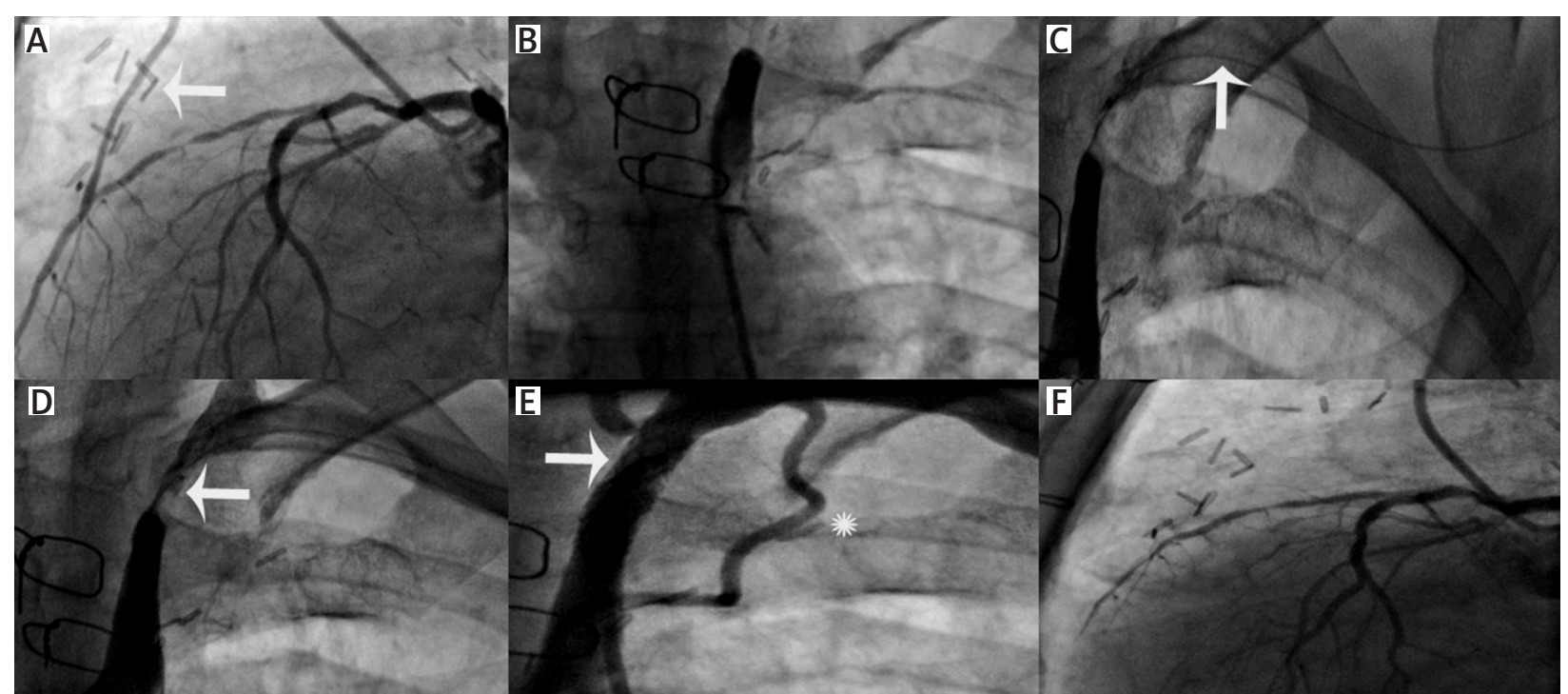

Figure 2. A - Retrograde flow of left internal thoracic artery (ITA) during left coronary angiography (arrow). B - Aortography shows $99 \%$ stenosis of left subclavian artery. C - Passing through the stenosis on the subclavian artery with a guidewire by the anterograde route (arrow). D - View of stenosis of left subclavian artery after balloon dilatation. E - Subclavian artery after stent implantation (arrow) and anterograde flow of left ITA (asterisk). F - Lack of retrograde flow of left ITA after left subclavian artery stenting

creased troponin, creatinine kinase $M B(C K-M B)$, and CK levels (50 ng/dl (normal range: $0.06 \mathrm{ng} / \mathrm{dl}$ ), $132 \mathrm{U} / \mathrm{l}$ (normal range: < $40 \mathrm{U} / \mathrm{l}), 1095 \mathrm{U} / \mathrm{l}$ (normal range: < 250 $\mathrm{U} / \mathrm{l})$, respectively), serum haemoglobin level $15.9 \mathrm{~g} / \mathrm{dl}$, and serum creatinine level $0.97 \mathrm{mg} / \mathrm{dl}$. He was diagnosed as non-ST elevation myocardial infarction. Coronary angiography revealed reversed flow through the left ITA conduit. Consequently, the patient was diagnosed as having coronary steal syndrome. Aortography showed 99\% stenosis of the left subclavian artery. After passing through the lesion with a guidewire by the anterograde route, we performed balloon dilatation, and balloon-expandable stent implantation for stenotic lesion. During the same procedure, control coronary left angiography revealed improvement of ITA flow (Figures $2 \mathrm{~A}-\mathrm{F}$ ). The patient was discharged after 5 days with optimal medication. 